\title{
An Accurate Experimental Determination of Interstitial Heat Transfer Coefficients of Ceramic Foams Using the Single Blow Method
}

\author{
K. Ando ${ }^{1}, \mathrm{H} . \mathrm{Hirai}^{2}$ and Y. Sano ${ }^{3, *}$ \\ ${ }^{1}$ Research Division, Nitto Kogyo Corporation, 2201 Kanihara, Nagakute-Cho, Aichi, 480-1189, Japan \\ ${ }^{2}$ Commercial \& Industrial Ventilation Engineering Section, Mitsubishi Electric Engineering Corporation, 3-40 Tegano, \\ Nakatsugawa-shi, Gifu, 508-0015, Japan \\ ${ }^{3}$ Department of Mechanical Engineering, Okayama University, 3-1-1 Tsushimanaka, Okayama, 700-8530, Japan
}

\begin{abstract}
An exhaustive experimental investigation has been carried out for accurate determination of interstitial heat transfer coefficients of ceramic foams in forced convective flows. The single-blow method was used, in which, the fluid temperature varies with time and convective heat transfer becomes time-dependent. The method results in a transient and conjugate heat transfer phenomena between the foam and fluid. These transient temperature data are then compared with the theoretical results to obtain the corresponding interstitial heat transfer coefficients between the fluid and foam solid surface. The interstitial coefficients thus determined are compared against available sets of experimental data, so as to examine the consistency among the reported experimental data.
\end{abstract}

Keywords: Porous media, Heat transfer enhancement, Single blow method, Temperature measurement.

\section{INTRODUCTION}

In order to use porous media for convective heat exchanger applications, one must estimate the interstitial heat transfer taking place between the solid and fluid phases. Naturally, the local thermal equilibrium assumption must be discarded, and the two energy equation model must be used to determine the distinct temperatures of the fluid phase and solid phase, and the local interstitial heat transfer between the two phases. Thus, for engineering applications of porous media, the evaluation of the interstitial heat transfer coefficients is equally important as that of stagnant thermal conductivities.

Fu et al. [1] carried out exhaustive measurements and correlated the interstitial heat transfer coefficients of cellular materials, which indicates the linear dependency of the Reynolds number on the Nusselt number. A general correlation for the volumetric heat transfer coefficient was introduced by Kamiuto and Yee [2] for open cellular porous materials, who indicated the Reynolds number exponent for the Nusselt number being close to 0.8 . They assembled experimental data reported by Younis and Viskanta [3], Ichimiya [4] and themselves, to find that all these experimental data for the volumetric heat transfer coefficient can be correlated fairly well using the strut diameter as a characteristic length for the open cellular materials. In recent years, some numerical attempts have been made to simulate the heat transport processes in foam materials (Zhiyong Wu [5], A. Kopanidis [6]).

*Address correspondence to this author at the Department of Mechanical Engineering, Okayama University, 3-1-1 Tsushimanaka, Okayama, 7008530 Japan; E-mail: sano_y@mech.okayama-u.ac.jp
Kuwahara and Fumoto [7] conducted a series of threedimensional numerical experiments by assuming a macroscopically uniform flow through the metal foams, so as to estimate the interstitial heat transfer coefficient between the fluid and foam solid surface.

Interstitial heat transfer coefficients are usually measured by the "single-blow method" (Liang and Yang [8]). The name "single-blow" is designated because a single fluid is employed in this method to heat the heat transfer surface. As illustrated in Fig. (1), in this method, inlet fluid temperature varies with time and convective heat transfer becomes timedependent, which results in a transient and conjugate heat transfer phenomena between the foam and fluid. A fluid flows steadily through a test core. Initially the fluid and the test core have the same uniform temperature. Then a fluid temperature variation is introduced at the inlet. Thereafter, the fluid and solid temperature histories at both inlet and outlet of the test core are measured continuously. These data are then compared with the theoretical results to obtain the corresponding interstitial heat transfer coefficients between the foam of solid surface and the fluid. Details of the method can be found in Wakao and Kaguei [9].

\section{EXPERIMENTAL PROCEDURE}

The experimental set-up used in this study is schematically shown in Fig. (2).

An air supplied by the blower is constantly heated by the heater. Then the hot air is mixed well as it passes through a mixer and filter. Thus, the well-mixed hot air flows through the test specimen. The thermally steady state can be reached after supplying the heated air for 4 to 5 hours. In the present 


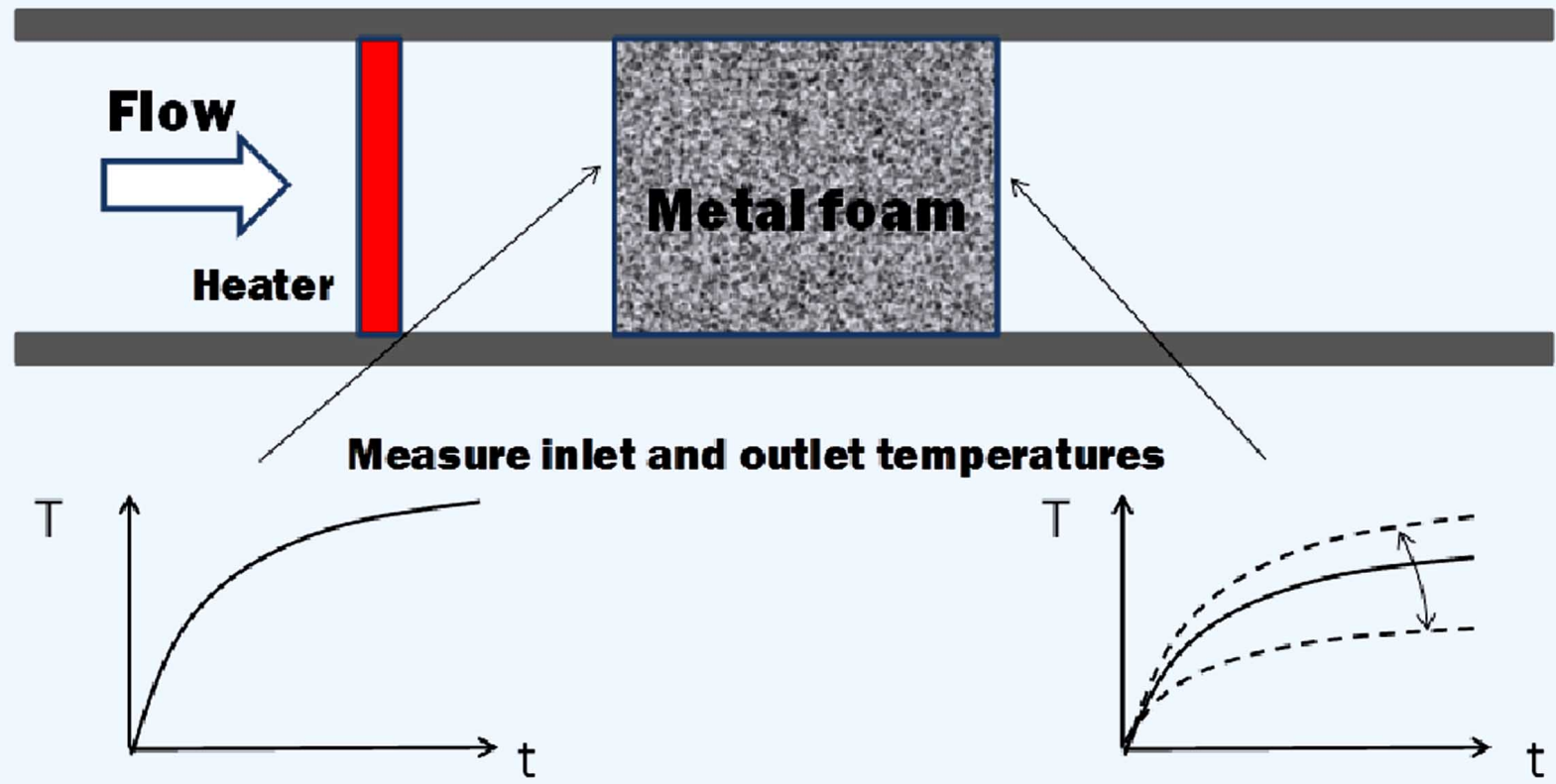

Adjust interstitial heat transfer coefficient

Fig. (1). Single blow method.

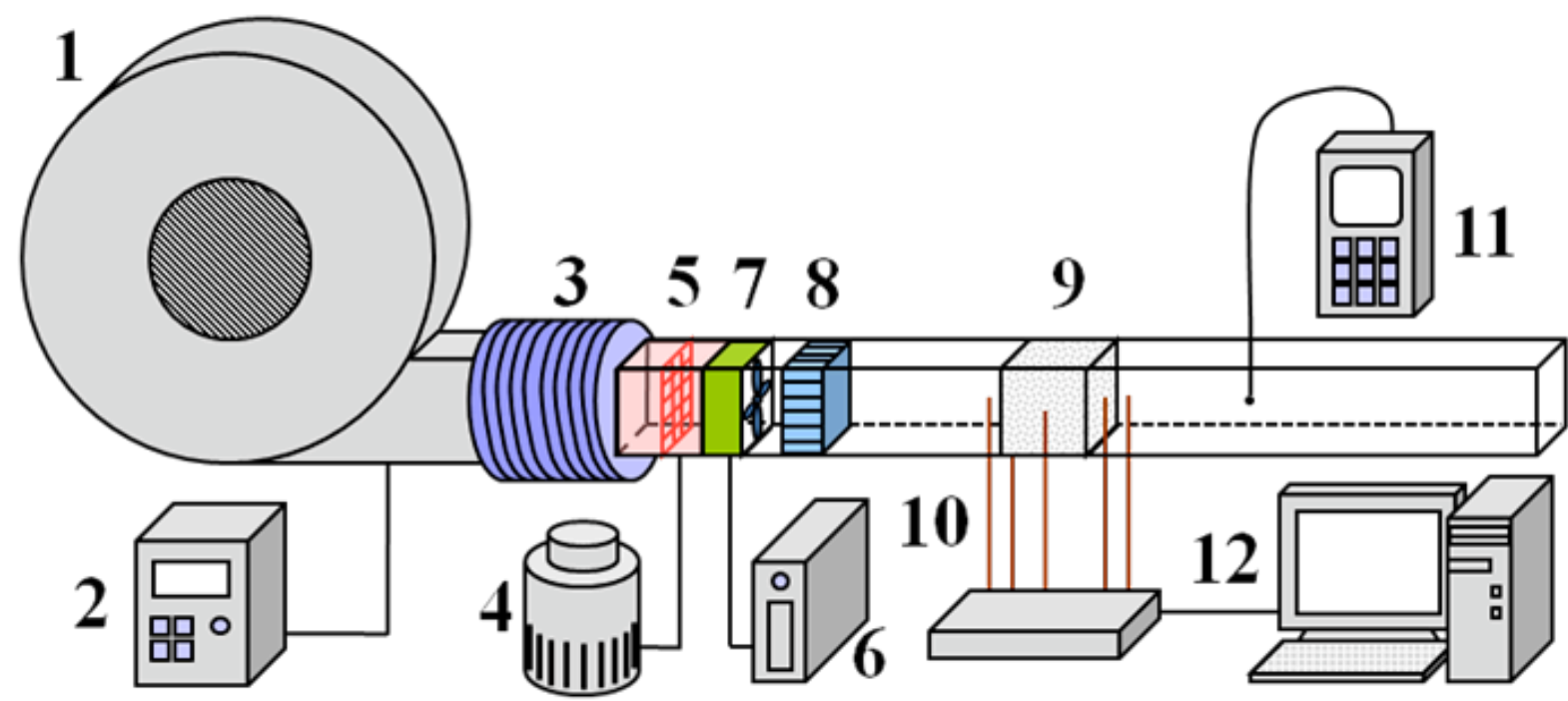

1 Blower, Blower, 2. Inverter, 3. Connecting duct, 4. Transformer, 5. Heater, 6. AD converter, 7. Mixer, 8. Filter, 9. Test specimen, Thermocouples, 11. Anemometer, 12. PC

Fig. (2). Experimental set-up.

experimental set-up, the heat supply is suddenly cut to introduce a fluid temperature variation at the inlet. Then, the air and foam temperature variations at both windward and leeward sides are monitored as indicated in the figure.

As prescribing the air and foam temperature variations at the inlet of the test specimen from the measurements, both air temperature $\langle T\rangle^{f}$ and foam temperature $\langle T\rangle^{s}$ at the leeward side are predicted and correlated with the temperatures predicted using the two-energy equation model:

$\rho_{f} c_{p f}\left(\frac{\partial\langle T\rangle^{f}}{\partial t}+u_{D} \frac{d\langle T\rangle^{f}}{d x}\right)=\varepsilon * k_{f} \frac{d^{2}\langle T\rangle^{f}}{d x^{2}}-h_{v}\left(\langle T\rangle^{f}-\langle T\rangle^{s}\right)$ $\rho_{s} c_{s} \frac{\partial\langle T\rangle^{s}}{\partial t}=\left(1-\varepsilon^{*}\right) k_{s} \frac{d^{2}\langle T\rangle^{s}}{d x^{2}}-h_{v}\left(\langle T\rangle^{s}-\langle T\rangle^{f}\right)$

where $u_{D}$ and $\varepsilon^{*}$ are the Darcian velocity and effective porosity (Yang and Nakayama [10]) respectively. The interstitial heat transfer coefficient $h_{v}$ is adjusted to fit the measured temperature developments at the leeward side of the test specimen with the predicted temperature responses, as shown in Figs. (3a) and (b).

For this typical case of ceramic foam with 6PPI, $\mathrm{L}=25 \mathrm{~mm}, \mathrm{u}_{\mathrm{D}}=4.95 \mathrm{~m} / \mathrm{s}$, the interstitial heat transfer coefficient is found to be $h v=15.3 \times 10^{4} \mathrm{~W} / \mathrm{m}^{3} \mathrm{~K}$. 


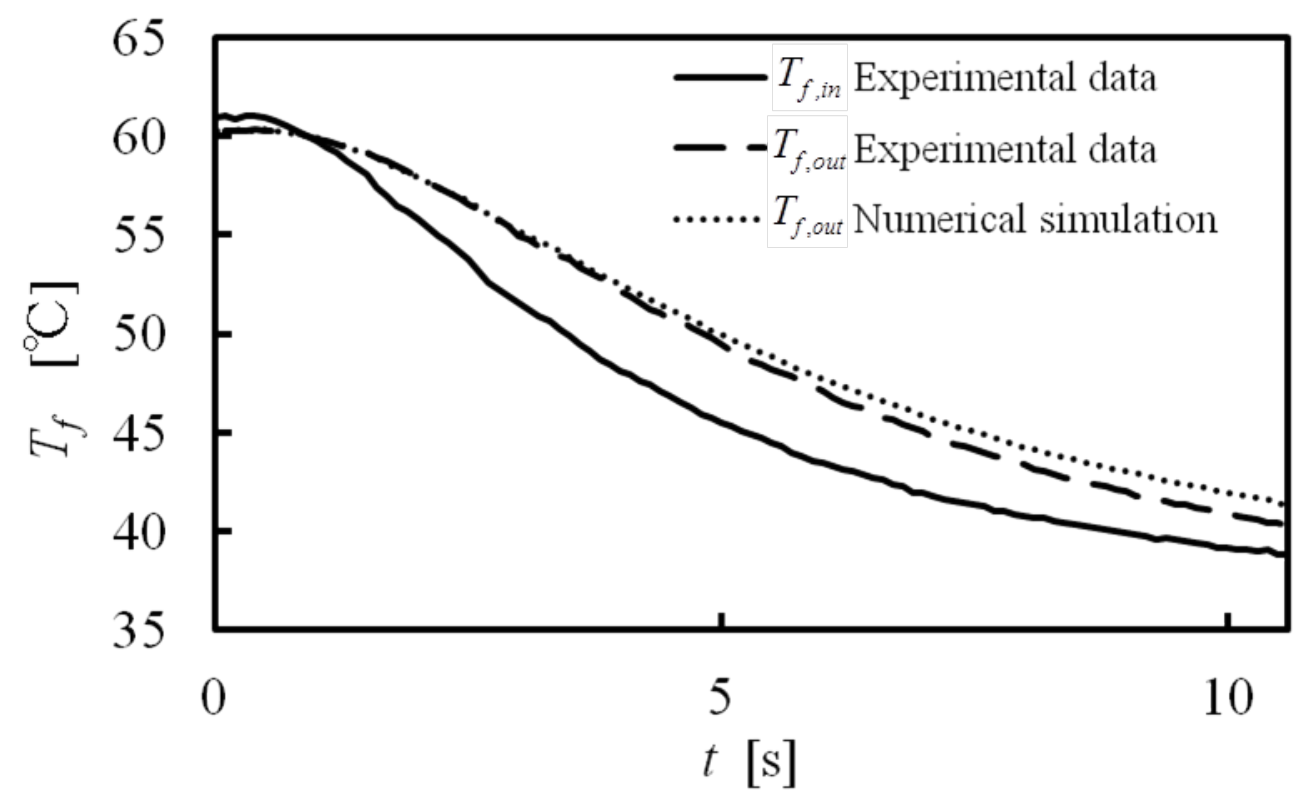

Fluid phase

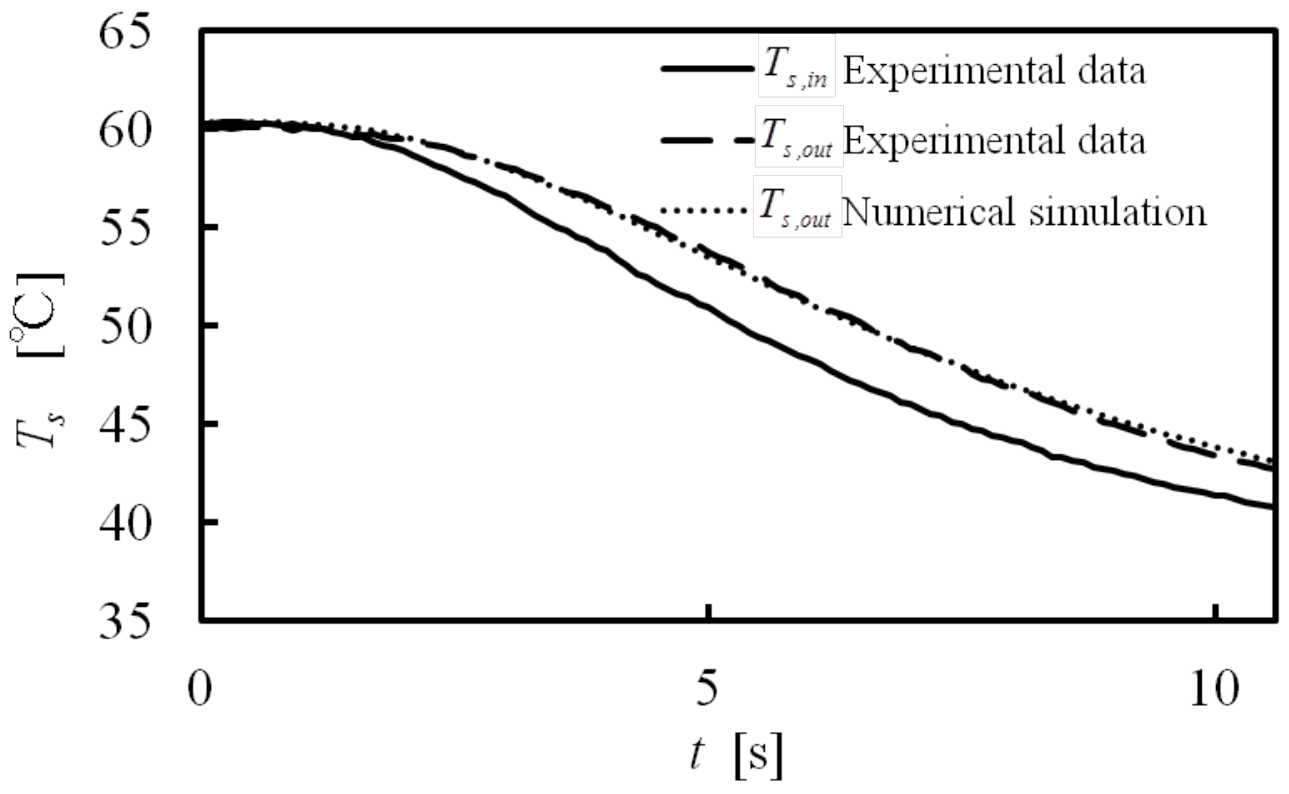

Solid phase

Fig. (3). Temperature developments (6PPI, $\left.L=25 \mathrm{~mm}, u_{D}=4.95 \mathrm{~m} / \mathrm{s}, h_{v}=15.3 \times 10^{4} \mathrm{~W} / \mathrm{m}^{3} \mathrm{~K}\right)$.

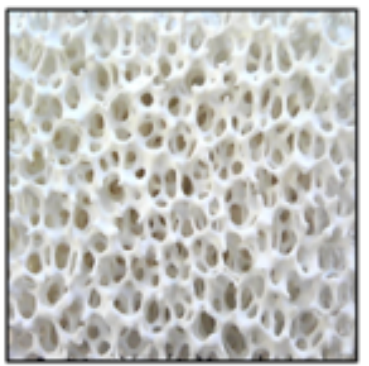

6PPI

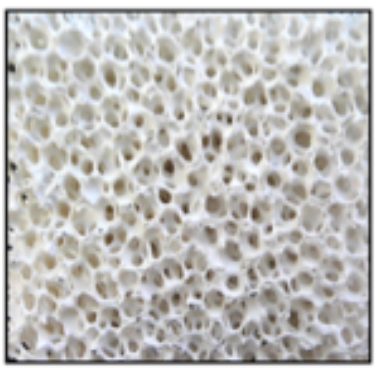

9PPI

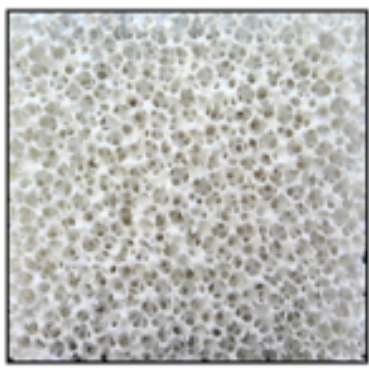

13PPI

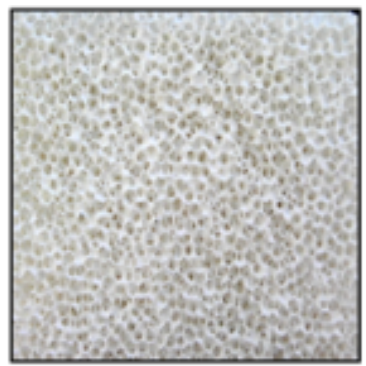

20PPI

Fig. (4). Test specimens of foam. 


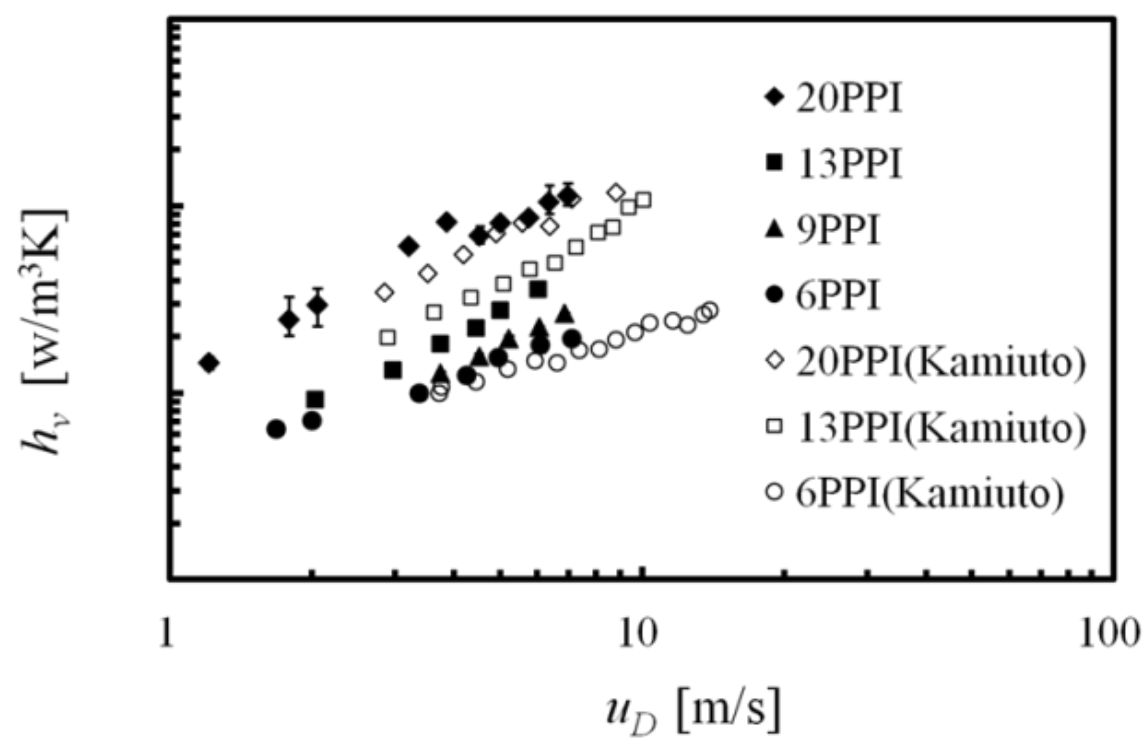

Fig. (5). Effect of the Daricain velocity on $h v$.

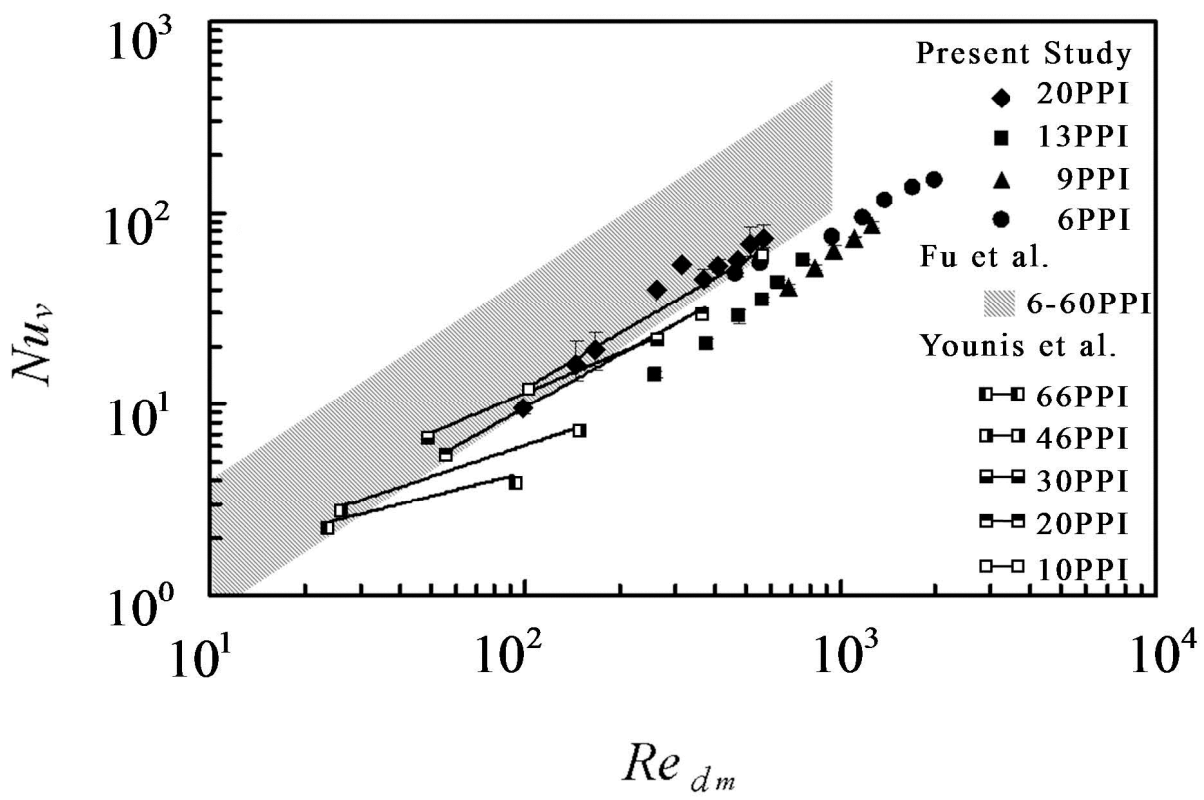

Fig. (6). Nusselt number vs Reynolds number.

\section{RESULTS AND DISCUSSION}

The test specimens of ceramic foam are shown in Fig. (4) for 6, 9, 13 and 20 PPI.

The effect of the Darcian velocity on the interstitial heat transfer coefficient $h v$ is illustrated in Fig. (5), in which a fairly good agreement can be seen between the present results and those reported Kamiuto et al. [2] using another transient thermal method. This indicates the validity of the present measuring system based on the single blow method.

All lines in the figure show mostly linear relationship between the Darcian velocity and the interstitial heat transfer coefficient. Nakayama et al. [11] theoretically investigated the interstitial heat transfer coefficient using the volume averaging theory. Using rigorous mathematical arguments, they explained the reason why the Reynolds number exponent of the Nusselt number expression for the case of low density consolidated porous media such as ceramic foam is close to unity, much greater than that of unconsolidated porous media such as packed beds.

Their Nusselt number and Reynolds number based on the pore diameter are defined as follows:

$N u_{v}=\frac{h_{v} d_{m}^{2}}{k_{f}}$

and

$R e_{d_{m}}=\frac{u_{D} d_{m}}{v}$

where the pore diameter of the ceramic foam is calculated from PPI as

$d_{m}=\frac{0.0254}{P P I} \sqrt{\frac{4 \varepsilon}{\pi}}$ 
All measured values of the interstitial heat transfer coefficient using ceramic foams $(6,9,13$ and $20 \mathrm{PPI})$ are processed to form the foregoing Nusselt number and are plotted against $R e_{d}$ in Fig. (6).

In the same figure, the experimental data reported by $\mathrm{Fu}$ et al. [1] and Younis and Viskanta [3] are also plotted for comparison.

The interstitial heat transfer coefficients obtained using the present experimental set-up for various ceramic foams are correlated in terms of the Nusselt number as follows:

6PPI:

$$
N u_{v}=0.055 \operatorname{Re}_{d_{m}}^{1.15} \quad\left(500 \leqq R e_{d_{\mathrm{m}}} \leqq 2000\right)
$$

9PPI:

$$
N u_{v}=0.012 \operatorname{Re}_{d_{m}}^{1.27} \quad\left(700 \leqq R e_{d_{\mathrm{m}}} \leqq 1300\right)
$$

13PPI:

$$
N u_{v}=0.015 \operatorname{Re}_{d_{m}}{ }^{1.21} \quad\left(300 \leqq R e_{d_{\mathrm{m}}} \leqq 800\right)
$$

20PPI:

$$
N u_{v}=0.342 \operatorname{Re}_{d_{m}}^{0.80} \quad\left(100 \leqq R e_{d_{\mathrm{m}}} \leqq 600\right)
$$

As can be seen from the foregoing experimental correlations, the resulting exponents of the Reynolds number for the Nusselt number expression are close to unity, or even higher than unity. This finding is consistent with the experimental data of Fu et al. [1] and some of Younis and Viskanta [3], as confirmed in the figure, and also with the theoretical consideration made by Nakayama et al. [11], who pointed out that the solid to fluid thermal diffusivity ratio should be sufficiently small, as in the case of ceramic foam, to acquire the linear relationship between the interstitial heat transfer coefficient and Darcian velocity.

It has been proven in this study that an accurate determination of the interstitial heat transfer rate in a porous foam is possible using the present measuring system based on the single blow method.

\section{CONCLUSIONS}

An experimental investigation on the interstitial heat transfer coefficient in porous foams has been carried out using the single blow method. Ceramic foams of $6,9,13,20$ PPI were placed in the tunnel of the experimental set-up to measure the temporal developments of the fluid and solid temperatures at the windward and leeward sides of the test section. Then, these transient temperature data are compared with the theoretical results to obtain the corresponding interstitial heat transfer coefficients between the foam solid surface and the fluid. The interstitial coefficients thus determined agree well with available sets of experimental data. The method developed in this can be used to explore the interstitial heat transfer within various foams.

\section{NOMENCLATURE}

$c \quad=\quad$ specific heat $(\mathrm{J} / \mathrm{kgK})$

$\begin{array}{lll}c_{p} & = & \text { specific heat at constant pressure }(\mathrm{J} / \mathrm{kgK}) \\ d_{m} & = & \text { pore diameter }(\mathrm{m}) \\ h_{v} & = & \begin{array}{l}\text { interfacial heat transfer coefficient } \\ \left(\mathrm{W} / \mathrm{m}^{3} \mathrm{~K}\right)\end{array} \\ k & = & \text { thermal conductivity }(\mathrm{W} / \mathrm{mK}) \\ T & = & \text { temperature }(\mathrm{K}) \\ u_{D} & = & \text { Darcian velocity }(\mathrm{m} / \mathrm{s}) \\ \varepsilon & = & \text { porosity }(-) \\ \varepsilon^{*} & = & \text { effective porosity }(-) \\ v & = & \text { density }\left(\mathrm{kg} / \mathrm{m}^{3}\right) \\ \rho & =\end{array}$

\section{SPECIAL SYMBOLS}

$\langle\phi\rangle^{f, s}=$ intrinsic average

\section{SUBSCRIPTS AND SUPERSCRIPTS}

$\begin{array}{lll}f & = & \text { fluid } \\ s & = & \text { solid }\end{array}$

\section{CONFLICT OF INTEREST}

The authors confirm that this article content has no conflicts of interest.

\section{ACKNOWLEDGEMENT}

Declared none.

\section{REFERENCES}

[1] X. Fu, R. Viskanta, and J. P. Gore, "Measurement and correlation of volumetric heat transfer coefficients of cellular ceramics", Exp. Therm. Fluid Sci., vol. 17, pp. 285-293, 1998.

[2] K. Kamiuto and S. S. Yee, "Heat transfer correlations for opencellular porous materials", Int. Commun. Heat Mass Transf., vol. 32, pp. 947-953, 2005

[3] L. B. Younis and R. Viskanta, "Experimental determination of the volumetric heat transfer coefficient between stream of air and ceramic foam", Int. J. Heat Mass Transf., vol. 36, pp. 1425-1434, 1993.

[4] K. Ichimiya, "A new method for evaluation of heat transfer between solid material and fluid in a porous medium", ASME J Heat Transf., vol. 121, pp. 978-983, 1999.

[5] Z. Wu, C. Caliot, G. Flamant, and Z. Wang, "Numerical simulation of convective heat transfer between air flow and ceramic foams to optimize volumetric solar receiver performances", Int. J. Heat Mass Transf., vol. 54, pp. 1527-1537, 2011.

[6] A. Kopanidis, A. Theodorakakos, E. Gavaises, and D. Bouris, "3D numerical simulation of flow and conjugate heat transfer through a pore scale model of high porosity open cell metal foam", Int. J. Heat Mass Transf., vol. 53, pp. 2539-2550, 2010.

[7] F. Kuwahara, and Y. Fumoto, "The effective pore diameter of a three-dimensional numerical model for estimating heat and fluid flow characteristics in metal foams", Open Transport Phenomena $J$. , In Press.

[8] C. Y. Liang, and W. J. Yang, "Modified single blow technique for performance evaluation on heat transfer surfaces", Trans. ASME J. Heat Transf., vol. 97, pp. 16-21, 1975. 
[9] N. Wakao and S. Kaguei, Heat and mass Transfer in packed beds, Gordon and Breach Science Pub: NY, 1982.

[10] C. Yang and A. Nakayama, "A synthesis of tortuosity and dispersion in effective thermal conductivity of porous media", Int. J. Heat Mass Transf., vol. 53 (15-16), pp. 3222-3230, 2010.
[11] A. Nakayama, K. Ando, C. Yang, Y. Sano, F. Kuwahara, and J. Liu, "A study on interstitial heat transfer in consolidated and unconsolidated porous media", Heat Mass Transf., vol. 45, no. 11, pp. 1365-1372, 2009.

(C) Ando et al.; Licensee Bentham Open.

This is an open access article licensed under the terms of the Creative Commons Attribution Non-Commercial License (http://creativecommons.org/licenses/by-nc/3.0/) which permits unrestricted, non-commercial use, distribution and reproduction in any medium, provided the work is properly cited. 